\title{
СУДЕЙСКОЕ УСМОТРЕНИЕ В РОССИЙСКОМ АРБИТРАЖНОМ И ГРАЖДАНСКОМ ПРОЦЕССЕ: ПРАВОВЫЕ И СОЦИАЛЬНЫЕ АСПЕКТЫ
}

\author{
А. В. Ведерников \\ Байкальский государственный университет, г. Иркутск, Российская Федерация
}

Информация о статье

Дата поступления

16 мая 2017 г.

Дата принятия к печати 6 июня 2017 г.

Дата онлайн-размещения 15 сентября 2017 г.

\section{Ключевые слова}

Судейское усмотрение; гражданский процесс; арбитражный процесс; метод аналогии в судебном процессе; конкретизация в судебном процессе

\begin{abstract}
Аннотация
Автор статьи обнаруживает увеличение доли и значения судейского усмотрения в российском арбитражном процессуальном и гражданском процессуальном законодательстве. Исследуется история вопроса и зарубежный буржуазный опыт. Буржуазные и англосаксонские подходы к судейскому усмотрению противопоставляются зрелым идеям советских процессуалистов, минимизирующих и отрицающих роль судейского усмотрения в процессе рассмотрения дела. Сделан вывод о постепенном переходе процессуальных норм и принципов на буржуазную идеологию. Дана классификация видов судейского усмотрения. Выделен спектр существования этих видов - от применения разъяснений до использования аналогии. Автор указывает, что за последние годы в отечественном праве метод аналогии превратился из сугубо материально-правового в общеправовой, т. е. процессуально-правовой. Выявлена стихийность формирования судейского усмотрения в современных социальных условиях, подкрепленных конституционными принципами. Идеологическое и культурное многообразие современного общества как реакция на советскую коммунистическую мораль не позволяет идейно направлять усмотрение конкретного судьи, потому излишняя активность законодателя по повсеместному внедрению судейского усмотрения в процессуальном законодательстве социально опасна.
\end{abstract}

\section{UDICIAL DISCRETION IN THE RUSSIAN ARBITRATION AND CIVIL LITIGATION PROCEEDINGS: LEGAL AND SOCIAL ASPECTS}

\author{
Aleksey V. Vedernikov \\ Baikal State University, Irkutsk, Russian Federation
}

Article info

Received

May 16, 2017

Accepted

June 6, 2017

Available online

September 15, 2017

\section{Keywords}

Judicial discretion; civil litigation process; arbitration litigation process; analogy in the judicial trial; concretization in the judicial proceeding

\begin{abstract}
The author of the article finds an increase in the share and importance of judicial discretion in the Russian arbitration procedural and civil procedural legislation. The history of the issue and foreign bourgeois experience are also being investigated. Bourgeois and Anglo-Saxon approaches to judicial discretion are contrasted with the mature ideas of Soviet legal proceedings specialists, which minimize and deny the role of judicial discretion in the process of reviewing the case. The author makes a conclusion about the gradual transition of procedural norms and principles to bourgeois ideology and gives classification of types of judicial discretion. He also defines the spectrum of existence of these species - from the application of explanations to the use of analogy. The author points out that in recent years, in the domestic law, the analogy method has evolved from a purely material legal to a general legal one, i.e. - and procedural legal. The spontaneity of
\end{abstract}


the formation of judicial discretion in modern social conditions, backed by constitutional principles, has been revealed. The ideological and cultural diversity of modern society, as a reaction to Soviet communist morality, does not allow ideologically to guide the discretion of a particular judge, therefore the excessive activity of the legislator in the widespread introduction of judicial discretion in procedural legislation is socially dangerous.

Элемент судейского усмотрения присущ современному судебному процессу в России. В некоторых процессуальных нормах прямо указывается на применение судейского усмотрения, но чаще необходимость «смотреть» и, как следствие, «усматривать» вытекает из диспозиции той или иной процессуальной нормы.

Общеизвестно, что повязка на глазах Фемиды, ради соблюдения равенства сторон, заставляет ее слушать, но не смотреть. Значит, судейское "усмотрение», появляясь в процессе, посягает на процессуальное равноправие. Например, это предусмотрено при рассмотрении вопроса о выдаче судебного приказа. Так, в гражданском процессе судья отказывает в принятии заявления о вынесении судебного приказа, если из заявления и представленных документов усматривается наличие спора - праве (ст. 125 ГПК РФ'). Аналогичные нормы содержатся в ст. 229.4 АПК Рф² и ст. 123.4 КАС РФ³. Сходный пример связан с допросом несовершеннолетнего свидетеля. По ст. 179 ГПК РФ «допрос свидетеля в возрасте до четырнадцати лет, а по усмотрению суда и допрос свидетеля в возрасте от четырнадцати до шестнадцати лет производятся с участием педагогического работника, который вызывается в суд".

Другая ситуация - необходимость "усмотрения", вытекающая из смысла нормы, - встречается чаще. Например, в п. 3 той же статьи 179 ГПК РФ указано: “Свидетель, не достигший возраста шестнадцати лет, по окончании его допроса удаляется из зала судебного заседания, за исключением случая, если суд признает необходимым присутствие этого свидетеля в зале судебного заседания». Прямо на необходимость проявить здесь усмотрение вроде бы законодатель суду не указал, но в начале ст. 179 порядок

1 Гражданский процессуальный кодекс Российской Федерации : федер. закон от 14 нояб. 2002 г. № 138Ф3 // Собрание законодательства РФ. 2002. № 46. СТ. 4532.

2 Арбитражный процессуальный кодекс Российской Федерации : федер. закон от 24 июля 2002 г. № 95-Ф3 / / Там же. № 30, ч. 1. Ст. 3012.

3 Кодекс административного судопроизводства Российской Федерации : федер. закон от 8 марта 2015 г. № 21-Ф3 / / Там же. 2015. № 10. Ст. 1391. допроса уже определен “усмотрением». Логично, что и завершать эту процедуру суд будет подобно тому, как начал. Аналогично норма сформулирована в ст. 162 КАС РФ и ст. 280 УПК РФ 4 .

Анализируя «судейское усмотрение» лингвистически, можно противопоставить его предварительному усмотрению законодателя. Предполагая, моделируя возможную ситуацию, законодатель создает, т. е. предусматривает, норму. Если сложившиеся общественные отношения не вписываются в предварительно усмотренные (т. е. предусмотренные) законодателем, то суду приходится усматривать... Переходить, так скажем, в «ручной» режим управления общественными отношениями.

В Толковом словаре В. Даля «усмотреть, усматривать» означает "увидеть, открыть, распознать, заметить». Например, «он сделал это по своему усмотрению, как счел за лучшее; убедиться в чем-либо умственно; наблюдать за чем-либо, смотреть» [1, с. 513].

В Словаре русского языка С. И. Ожегова слово "усмотрение» рассматривается в нескольких значениях: решение, заключение, мнение [2, с. 729].

Исторически институт судейского усмотрения уходит в самую глубь веков. Древнейшие упоминаемые судейства («суд Париса», “Соломоновы решения») есть решения, суждения как результат наблюдения, усмотрения. В условиях несложившегося материального и процессуального права иначе и быть не могло. Постепенно доля усмотрения уменьшалась за счет «предусмотрительных» предписаний. В прецедентной правовой системе судейское усмотрение продолжает оставаться одним из стержневых, неотъемлемых элементов, в континентальной его доля может быть сведена до минимума.

Буржуазные и ранние советские авторы положительно относились к предоставлению суду возможности усмотрения. Позднее в советской процессуальной науке сформировалось отрицательное отношение к подобно-

${ }^{4}$ Уголовно-процессуальный кодекс Российской Федерации : федер. закон от 18 дек. 2001 г. № 174-Ф3 // Российская газета. 2001. 22 дек. 
го рода «вольностям». Так, И. А. Покровский под судейским усмотрением понимал «право более свободного истолкования, восполнения и даже исправления закона сообразно требованиям справедливости и велению судейской совести» [3, с. 205].

Американские юристы указывали на свободное усмотрение судей как в вопросе установления фактов по делу, так и в вопросе применения норм права [4, р. 14]. Опираясь на свободу судейского усмотрения, в прецедентной системе права они пришли к выводу о возможности создания юстиции без права [5, р. 56].

К. И. Комиссаров, критикуя эти «буржуазные» идеи, отмечает, что советская процессуальная наука, и в частности теория судебных доказательств, «долгое время находилась под сильным влиянием субъективизма Вышинского, который считал, что суд должен быть максимально свободен в оценке доказательств, что нужно предоставить судье возможно больший в наших условиях простор судебной оценки доказательств» [6, с. 49]. Проповедуя, как представляется, концепцию объективной истины в судебном процессе, К. И. Комиссаров резюмировал, что «оценку доказательств в социалистическом правосудии нельзя относить к области судебного усмотрения... Суд при всей свободе своих убеждений обязан в действительности достоверное признать достоверным, сомнительное - сомнительным, ложное - ложным» [там же, с. 50].

По мнению К. И. Комиссарова, судебное усмотрение представляет собой «предоставленное суду правомочие принимать, сообразуясь с конкретными условиями, такое решение по вопросам права, возможность которого вытекает из общих и лишь относительно определенных указаний закона» [там же]. Соответственно, его назначение заключается в том, чтобы «в случаях отсутствия прямого, абсолютно определенного указания найти такое из ряда предполагаемых законом решений, которое наиболее точно соответствует идее законодателя» [7, с. 26].

Ряд советских юристов не считали возможным применять судейское усмотрение в судебном процессе. Задача суда и судей заключалась, по их мнению, лишь в «конкретизации» нормы. Эту позицию можно считать доминирующей в советской процессуальной науке второй половины XX в. Примеры такой конкретизации - случаи взыскания алиментов (когда законом не установлена твердая сумма), взыскания вознаграждения за причиненный вред, дела о выделе и разделе имущества [8, с. 95]. Причины и предпосыл- ки этой конкретизации кроются в отрицании советскими правоведами деления права на публичное и частное. Деликтные, семейные и прочие глубоко частные правоотношения регулировались в Советской стране подобно публичным. Однако урегулировать такие общественные отношения можно было только грубо и примитивно, задав общее направление. Необходимость в конкретизации такого общего направления вызывалась «частной неурегулированностью содержания правоотношения» [9, с. 86-87].

Конкретизируя правовую норму, суд, как считалось, применял не собственное усмотрение, а руководствовался позицией вышестоящих судов. Считалось, что «конкретизация начинается в судах первой инстанции и завершается изданием пленумом Верховного суда "правоконкретизирующего положения"» [10, с. 6-7]. Позиция эта справедливо критиковалась и ранее [6, с. 52]. Во-первых, «издание положений» Верховным судом стирает границу между судебной и законодательной деятельностью. Хотя вся власть в социалистической России и принадлежала Советам, техническое разделение государственной власти все же существовало. Кроме того, суд был при депутатах, а не наоборот. Депутаты Верховного Совета иногда проводили судебные процессы, это соответствовало иерархии. Но суд, по этой логике, не мог забрать нормотворческие функции у Советов. Во-вторых, конкретизация просто по своей сути не может быть общей, универсальной. «Конкретизация прав и обязанностей осуществляется судом не иначе, как при рассмотрении конкретного дела, ибо пока действует определенная ситуационная норма, существует и необходимость конкретизации ее применительно к каждому частному случаю» [там же, с. 53].

Тем не менее и современные ученые указывают на объективную зависимость судов от вышестоящих инстанций и противоречащие этому требования Конституции РФ. Д. Б. Абушенко пишет: «Деятельность нижестоящих судов в итоге направляется волей Высшего Арбитражного Суда РФ и Верховного Суда РФ (которая может в принципе и искажать закон). При этом в случае возможных противоречий в отношении к определенным вопросам правоприменения между позицией высшей судебной инстанции (формы ее изложения могут быть различны) и позицией самого судьи, последний косвенно принуждается следовать подходу, выработанному высшей судебной инстанцией» [11, с. 24-25]. 
Bсе же следует заключить, что применение судом четких указаний, чьи бы они ни были (от законодателя или от вышестоящего суда), нельзя считать конкретизацией и уж тем более применением судейского усмотрения. Ключевым критерием выступает не источник "указания», а его фрорма.

Выше мы выявили несколько форм легализации судейского усмотрения: прямое предписание судье проявить внимание и применить усмотрение (суд по своему усмотрению проводит...); завуалированное предписание суду, «намек» на возможность проявить усмотрение (суд может..., суд вправе...); норма, для применения которой нужна конкретизация (если только нету «конкретизирующего предписания»). Далее следует упомянуть альтернативную норму.

Пункт 1 ст. 87 АПК РФ гласит: «При недостаточной ясности или полноте заключения эксперта, а также при возникновении вопросов в отношении ранее исследованных обстоятельств дела может быть назначена дополнительная экспертиза, проведение которой поручается тому же или другому эксперту». В приведенном примере вначале сформулирован «намек» на усмотрение («может быть назначена»), а далее («тому же или другому эксперту») альтернатива. Очевидно, что выбор между первоначальным или «новым» экспертом суд осуществляет по своему усмотрению.

Отдельно следует сказать о применении аналогии. Об изменении принципиальных подходов законодателя здесь нельзя умолчать. Метод аналогии в праве носит межотраслевой, а возможно, и общеправовой характер. Применяют его далеко не только судьи. Нельзя рассматривать применение метода аналогии закона и (или) аналогии права только как разновидность судебного усмотрения. Вместе с тем указание в процессуальном законе на возможность применения аналогии следует считать формой легализации судейского усмотрения.

На протяжении долгого времени до недавнего прошлого применение аналогии допускалось лишь в материальном праве. Процессуальная форма, напротив, была строга, потому судебный процесс не регулировался по аналогии. Так, действовавший до 2003 г. ГПК РСФСР предписывал: «Порядок производства по гражданским делам во всех судах РСФСР определяется Основами гражданского судопроизводства Союза ССР и союзных республик и издаваемыми в соответствии с ними другими законами Союза ССР и Гражданским процессуальным кодексом РСФСР.
Законодательство о гражданском судопроизводстве устанавливает порядок рассмотрения дел по спорам, возникающим из гражданских, семейных, трудовых и колхозных правоотношений, дел, возникающих из административно-правовых отношений, и дел особого производства. Дела, возникающие из административно-правовых отношений, и дела особого производства рассматриваются по общим правилам судопроизводства за отдельными изъятиями, установленными законодательством Союза ССР и РСФСР.

Производство по гражданским делам ведется по гражданским процессуальным законам, действующим во время рассмотрения дела, совершения отдельных процессуальных действий или исполнения решения суда» (ст. 1 «Законодательство о гражданском судопроизводстве»)

Разрешая спор по существу и применяя нормы материального права, суд мог применить аналогию по ст. 10 ГПК РСФСР («Разрешение дел на основании действующего законодательства»): «В случае отсутствия закона, регулирующего спорное отношение, суд применяет закон, регулирующий сходные отношения, а при отсутствии такого закона суд исходит из общих начал и смысла советского законодательства».

Норма, допускающая процессуальную аналогию, появилась в «новом» ГПК РФ 2002 г. Пункт 4 ст. 1: «В случае отсутствия нормы процессуального права, регулирующей отношения, возникшие в ходе гражданского судопроизводства, федеральные суды общей юрисдикции и мировые судьи (далее также - суд) применяют норму, регулирующую сходные отношения (аналогия закона), а при отсутствии такой нормы действуют исходя из принципов осуществления правосудия в Российской Федерации (аналогия права)».

Можно сказать, что некогда жесткая процессуальная форма «обмякла». Спустя 13 лет эта норма появилась и в АПК Рф 6 .

Сама конструкция метода аналогии такова, что каких-либо предписаний от вышестоящих судов здесь быть не может, ибо если Верховный суд создаст норму, то эта норма заполнит пробел в законе, ранее «закрывавшийся» аналогией. Другой

${ }^{5}$ Гражданский процессуальный кодекс РСФСР : утв. ВС РСФСР 11 июня 1964 г. // Ведомости ВС РСФСР. 1964. № 24. Ст. 407 (утратил силу).

${ }^{6} \mathrm{O}$ внесении изменения в статью 3 Арбитражного процессуального кодекса Российской Федерации : феедер. закон от 29 июня 2015 № 195-Ф3 / / Собрание законодательства РФ. 2015. № 27. СТ. 3986. 
вопрос, что так нарушается принцип разделения власти в государстве, но это не тема настоящего исследования, а на практике такое случается.

Значит, применяя аналогию, судья действует именно по своему усмотрению. Роль и значение метода аналогии в современном судебном процессе растут, - это очевидно.

Без ответа остается вопрос о том, должно ли судейское усмотрение зависеть от личности судьи. Если решение этого вопроса «пустить на самотек», не замечать его, ответ будет положительный. Есть множество факторов, влияющих на становление личности, и двух полностью одинаковых «усмотрений» у разных людей не будет. Однако должно ли быть так в судебном процессе, да еще и при разрешении процессуального вопроса?

Очевидно, так быть не должно. Например, в СССР единообразие "усмотрения» достигалось применением коммунистической идеологии. Так, у А. Т. Бонера читаем: «Под судебным усмотрением следует понимать предоставленное суду правомочие решать правовые вопросы, исходя из обстоятельств дела, общих положений закона, принципов права, экономических законов социализма и норм коммунистической морали» [12, с. 42-43]. Ныне такого культурного единства нет. Не вдаваясь в дискуссию о соотношении морали, идеологии и нравственности, заметим, что борьба с «экономическими законами социализма» и «коммунистической моралью» возникла внутри нашего общества. В какой-то мере экономика «точила» мораль, и наоборот.
Возврат к прежней единой идеологии сейчас не представляется возможным. Это закреплено в Конституции и следует из нее. В Российской Федерации признается идеологическое многообразие. Никакая идеология не может устанавливаться в качестве государственной или обязательной (пп. 1 и 2 ст. 13 Конституции РФ). Каждому гарантируется свобода совести, мысли и слова (ст. 28 и 29 Конституции РФ).

Таким образом, резюмируем: институт судейского усмотрения (включая метод применения процессуальной аналогии) прочно интегрирован в современный судебный (гражданский и арбитражный) процесс. При этом современное общество, основывающееся на конституционном строе (ст. 16 Конституции РФ), не имеет четких и однозначно общих культурно-идеологических ориентиров. «Острота зрения» судейского усмотрения зависит теперь главным образом от личности судьи. Личность эта все меньше защищается строгой формой процессуального закона. Благодаря внедрению процессуальной аналогии форма смягчена, а пробелы в ней судья закрывает «своим усмотрением».

Описанная тенденция социально опасна. Недовольство усердием или пассивностью того или иного судьи может вылиться в попытку любыми путями отстранить конкретного судью от рассмотрения конкретного дела. Отход от социалистической формы хозяйствования в капитализм породит те проблемы, о которых в начале XX в. рассуждали процессуалисты (юстиция без права).

\section{СПИСОК ИСПОЛЬЗОВАННОЙ ЛИТЕРАТУРЫ}

1. Даль В. И. Толковый словарь живого великорусского языка : в 4 т. / В. И. Даль. — М. : Рус. яз., 1980. T. $4 .-684 \mathrm{c}$.

2. Ожегов С. И. Словарь русского языка / С. И. Ожегов. - 17-е изд. - М. : Рус. яз., 1985. - 797 с.

3. Покровский И. А. Основные проблемы гражданского права / И. А. Покровский. - Пг. : Юрид. кн. склад «Право», 1917. - 234 с.

4. Pound R. Social Control through Law / R. Pound. - New Haven : Yale Univ. Press ; London : Humphrey Milford: Oxford Univ. Press, 1942. - $138 \mathrm{p}$.

5. Frank J. Courts on trial: Myth and Reality in American Justice [Electronic resource] / J. Frank // Indiana Law Journal. - 1949. - № 114. - Mode of access: https://books.google.ru/books?id=UJgmr316SVoC\&p$\mathrm{g}=\mathrm{PA} 14 \& \mathrm{hl}=$ ru\&source=gbs_toc_r\&cad=3\#v=onepage\&q\&f=false.

6. Комиссаров К. И. Судебное усмотрение в советском гражданском процессе / К. И. Комиссаров // Советское государство и право. - 1969. - № 4. - С. 49-56.

7. Комиссаров К. И. Задачи судебного надзора в сфере гражданского судопроизводства / К. И. Комиссаров. - Свердловск : Изд-во Свердл. юрид. ин-та, 1971. - 167 с.

8. Зейдер Н. Б. Судебное решение по гражданскому делу / Н. Б. Зейдер. - М. : Юрид. лит., 1966. - 190 с.

9. Кац А. К. Конкретизирующая деятельность суда и семейные правоотношения с частично неурегулированным содержанием / А. К. Кац / / Правоведение. - 1964. - № 2. - С. 86-87.

10. Безина А. Конкретизация права в судебной практике / А. Безина, В. Лазарев / / Советская юстиция. 1968. - № 2. - С. 6-7.

11. Абушенко Д. Б. Судебное усмотрение в гражданском и арбитражном процессе / Д. Б. Абушенко. М. : Норма, 2002. - 176 с.

12. Боннер А. Т. Применение нормативных актов в гражданском процессе / А. Т. Бонер. - М. : Юрид. лит., 1980. -160 c. 


\section{REFERENCES}

1. Dal V. I. Tolkovyi slovar' zhivogo velikorusskogo yazyka [The Explanatory Dictionary of the Living Great Russian Language]. Saint Petersburg, Russkii yazyk Publ., 1980. Vol. 4. 684 p.

2. Ozhegov S. I. Tolkovyi slovar' russkogo yazyka [Dictionary of the Russian Language]. $17^{\text {th }}$ ed. Moscow, Russkii yazyk Publ., 1985. 797 p.

3. Pokrovskii I. A. Osnovnye problemy grazhdanskogo prava [The Main Problems of Civil Law]. Petrograd, Legal Book Store «Pravo» Publ., 1917. 234 p.

4. Pound R. Social Control through Law. New Haven, Yale University Press; London, Humphrey Milford, Oxford University Press, 1942. $138 \mathrm{p}$.

5. Frank J. Courts on trial: Myth and Reality in American Justice. Indiana Law Journal, 1949, no. 114. Available at: https: / /books.google.ru/books?id=UJgmr316SVoC\&pg=PA14\&hl=ru\&source=gbs_toc_r\&cad=3\#v=onepage $q \mathrm{q} \delta \mathrm{f}=\mathrm{false}$.

6. Komissarov K. I. Judicial Discretion in the Soviet Civil Procedure. Sovetskoe gosudarstvo i pravo = Soviet State and Law, 1969, no. 4, pp. 49-56. (In Russian).

7. Komissarov K. I. Zadachi sudebnogo nadzora v sfere grazhdanskogo sudoproizvodstva [The Tasks of Judicial Supervision in the Sphere of Civil Proceedings]. Sverdlovsk State Law University Publ., 1971. 167 p.

8. Zeider N. B. Sudebnoe reshenie po grazhdanskomu delu [Judgement in a Civil Case]. Moscow, Yuridicheskaya literatura Publ., 1966. $190 \mathrm{p}$.

9. Kats A. K. Specifying Activities of the Court and Partially Unresolved Family Relations. Pravovedenie $=$ Jurisprudence, 1964, no. 2, pp. 86-87. (In Russian).

10. Bezina A., Lazarev V. Specification of Law in Court Practice. Sovetskaya yustitsiya = Soviet Justice, 1968, no. 2, pp. 6-7. (In Russian).

11. Abushenko D. B. Sudebnoe usmotrenie $v$ grazhdanskom $i$ arbitrazhnom protsesse [Judicial Discretion in Civil and Arbitration Proceedings]. Moscow, Norna Publ., 2002. 176 p.

12. Bonner A. T. Primenenie normativnykh aktov $v$ grazhdanskom protsesse [The Application of Regulations in Civil Proceedings]. Moscow, Yuridicheskaya literatura Publ., 1980. 160 p.

\section{Информация об авторе}

Ведерников Алексей Викторович - кандидат юридических наук, доцент, кафедра предпринимательского и финансового права, Байкальский государственный университет, 664003, г. Иркутск, ул. Ленина, 11, e-mail: all_you_need@mail.ru.

\section{Для цитирования}

Ведерников А. В. Судейское усмотрение в российском арбитражном и гражданском процессе: правовые и социальные аспекты / А. В. Ведерников / / Известия Байкальского государственного университета. - 2017. - Т. 27, № 3. - С. 419-424. DOI: $10.17150 / 2500-2759.2017 .27(3) .419-424$.

\section{Author}

Aleksey V. Vedernikov - PhD in Law, Associate Professor, Department of Business and Financial Law, Baikal State University, 11 Lenin St., 664003, Irkutsk, Russian Federation, e-mail: all_you_need@mail.ru.

\section{For Citation}

Vedernikov A. V. Judicial Discretion in the Russian Arbitration and Civil Litigation Proceedings: Legal and Social Aspects. Izvestiya Baykal'skogo gosudarstvennogo universiteta $=$ Bulletin of Baikal State University, 2017, vol. 27, no. 3, pp. 419-424. DOl: 10.17150/2500-2759.2017.27 (3).419-424. (In Russian). 